\title{
A Review of the Studies on the Frequent Administrations of English Tests
}

\author{
Mostafa Hosseyni Ramshe \\ University of Isfahan, Iran
}

\begin{abstract}
The aim of this paper is to give a review of the studies which have been conducted on the role of the frequent administrations of tests. This includes studies on the effect of testing frequency on students' scores, anxiety, motivation, preparation, class participation, long-term retention of the materials, and the effect of the feedback which is given based on students' performance on these frequent tests. It also gives a brief summary of different types of test-anxious students and models of test anxiety.
\end{abstract}

Index Terms - testing frequency, anxiety, motivation

\section{INTRODUCTION}

One of the essential parts of every curriculum is evaluation. It helps us make sure whether our objectives have been fulfilled or not. One type of evaluation is to measure students' learning through paper and pencil tests. According to Bachman (1990), "a test is a measurement instrument designed to elicit a specific sample of an individual's behavior" ( $p$. 20).In some educational contexts, teachers test their students so frequently that it becomes a weekly activity, whereas in other contexts tests may only be used at the end of the school year. Research has shown that frequent administrations of tests like weekly tests lead to better scores on the final exam. (e.g., Butler \& Roediger, 2007; Deck 1998; Shirvani, 2009). Research has also indicated that frequent test administrations make students more motivated to study for their courses (e.g., Duckworth \& Kenneth, 1986; Brookhart \& DeVoge, 1999).

Frequent administrations of tests seem to be closely related to the notion of spaced or distributed practice method of memorization or what Dempster (1988) refers to as the 'spacing effect'. According to this notion taking different tests which include only a particular part of knowledge and are administered with a specific time interval compared with cases when a test includes different aspects of knowledge at a time can lead to a better learning.

In this respect, studies have shown that through frequent tests, students would be encouraged to keep up their study (Weimer, 2003). These results have further shown that frequent test administrations improve both grades and motivation.

In addition, Bangert-Drowns et al. (1991) in their meta-analysis of frequent administrations of tests showed that most of the studies on the effect of frequent testing report a positive effect of testing on achievement. While most of the studies show a positive effect on achievement, the effect size for this meta-analysis is not considerable.

Studies show that frequent administrations of tests can bring several advantages to the students. Dustin (1971) concluded that anxiety decreases through the administrations of frequent tests. A study by Clump, Bauer, \& Alex (2003) showed that testing frequency increases students' class attendance. In addition frequent testing can provide students, teachers, parents, and schools with beneficial feedback on students' performance (Bangert-Drowns et al., 1991). On the other hand, there are other researchers such as Marshall (2007) who believe that taking too many tests does not lead to valuable learning because teachers put all of their efforts teaching the information which is needed for passing the test and students study those parts which are important for those tests. So, more studies are needed to investigate the role of frequent administrations of tests.

Moreover, frequent administrations of tests can influence the motivation of students both directly and indirectly: A direct effect is through increasing student's anxiety. Based on 'interference model' students do poorly on tests because they cannot avoid the irrelevant thoughts that is going on in their mind during taking a test (Zeidner, 1998).This anxiety can be a stable trait of that individual or something that only occurs as a result of a specific situation (Brown, 2007).An indirect effect can be through their effects on teachers and curricula (Harlen \& Crick, 2002).

Zeidner (1998) in his book, test anxiety, mentions five types of test -anxious students:

A) Examinees with deficient study and test-taking skills: students' poor performance results from lack of adequate acquisition (encoding), organization/rehearsal (study skills), and retrieval/application during a test. These students are likely to do poorly in both evaluative and non-evaluative situations, because they do not organize the material well in the first stage (Paulman \& Kennely, 1984). Examinees experience anxiety blockage and retrieval problems. This includes students who have adequate study skills, but suffer from anxiety blockage and cannot retrieve information well during an exam (Benjamin et.al., 1981). These students cannot control the stress and pressure of an evaluative situation.

B) Failure accepting examinees: failure acceptors are those who have poor study skills and low academic ability. Because of the large number of repeated failures in the pats, they accept low ability as the first explanation for their failures. These students do not struggle to keep their worth through ability and because of frequent failures, they are 
sure of their incompetency (Covington, 1992). Failure acceptors neither become that much proud, when they succeed nor that much shameful, when they fail.

C) Failure-avoiding examinees: these students need success in order to establish a sense of self-worth by ignoring the probability of failure (Covington, 1992). These students think that, they should study very hard for an exam, because it increases the prospect of success. But this amount of study can be a danger for them, because the more they study, they see it as inadequate and this can create anxiety for them. This anxiety is because of this fact that students are scared of being evaluated as incompetent by others and this hurts the self-worth that they have provided for themselves.

D) Self-handicappers: self-handicapping strategies in an exam situation are defined as creating obstacles to performance, so that the student has an excuse for the potential failure or other negative consequences. So, test-anxiety might be used as an explanation for failure. When these students fail, they exaggerate the role of anxiety and deemphasize the role of effort and ability (Smith et.al, 1982).

E) Perfectionistic overstrivers: these students have high academic standards, exaggerated expectations, and doubt about the quality of academic performance (Blatt, 1995 \& Covington, 1992). According to Blatt (1995), two groups of perfectionists exist: 'adaptive' and 'nonadaptive' perfectionists. Adaptive perfectionists' hard efforts, gives them pleasure and when they succeed, a feeling of satisfaction arises in them. However, maladaptive perfectionists experience a feeling of fear that arises from not meeting the self-imposed or externally-imposed standards and forces them to selfdefeating overstriving. For these students no effort is ever sufficient. Anything other than a perfect score is considered as complete failure and results in severe upset and self-criticism (Oliver, 1975). Hewitt and Flett (1991) also proposed two types of perfectionists: self-related perfectionists are characterized by high self-imposed unrealistic standards and they cannot accept flaws or failure. The second type is socially prescribed perfectionists which are characterized by the belief that they should fulfill others' expectations which are exaggerated, unrealistic, and difficult to meet. These expectations are externally imposed, uncontrollable, and lead to feelings of failure, anxiety, and hopelessness.

Zeidner (1988) also mentions different models of test anxiety which I briefly discuss them here:

Deficit models: these models explain test anxiety in terms of the lack of enough skills or attention. Here are some of these models:

Cognitive - attentional (interface) model: this model proposes that high test anxiety is the result of failing to direct one's attention to an evaluative situation and the task at hand. Based on this model low-anxiety test takers are successful in leading their attention to that test and have a better understanding of that situation (Weinstein, Cubberly \& Richsrdson, 1982).

Sill-deficit models: these models postulate that lack of enough study skills and test taking strategies lead to the poor organization and intake of the material and consequently poor performance on the test (Paulman \& Kennelly, 1984). According to this model because students are aware of the fact that their skills are not adequate enough, they become more and more anxious.

Contemporary cognitive-motivational models: these models explain test anxiety in terms of the actions which tests takers take to self-regulate their thoughts or to maintain their self-worth. Here are some of these models:

Self-regulation model: According to this model less anxious test takers are able to keep their confidence in an evaluative situation (to self-regulate), whereas anxious test takers fail to perform successfully and keep their confidence (Carver \& Scheier, 1988).

Self-worth model: This model proposes that individuals try to maintain their self-worth and their positive image of themselves in a testing condition. Not being able to perform successfully in such situations would lead to harming this positive self-image and an increase in their anxiety (Covington, 1992).

Transactional models: In these models test anxiety is the result of several factors interacting with each other. Here are some of these models:

Spielberger's state-trait model: This model is based on the distinction between state anxiety and trait anxiety (Spielberger et al., 1978). State anxiety is a kind of anxiety that is related to a particular situation and is not stable. Trait anxiety is a kind of anxiety that is part of an individual's personality and is stable across different Situations. Based on this model test anxiety is a situation specific form of trait anxiety which occurs in a variety of situations. On the other hand state anxiety refers to a level of anxiety in a particular evaluative situation such an exam for the entrance of an important university and it does not happen in all situations. High test anxious students' experience is the result of high trait anxiety.

Transactional process model: According to this model test anxiety consists of different factors: a) personality variables and situational conditions (Spielberger \&Vagg, 1995). b) The mediating emotional and cognitive processes involved. c) The correlates and short-term consequences of test anxiety d) various emotion-focused and cognitivefocused intervention strategies designed to help lessen the unfavorable consequences of test anxiety. Based on this model in a testing situation, test-takers will feel a certain amount of anxiety based on individual differences in test anxiety and situational factors. The situational factors include the subject of the test, study and test-taking attitudes and test-taking skills. Students who possess good test-taking skills will perceive a testing situation as less threatening. To the extent that a testing situation is appraised as threatening, state anxiety and its cognitive realizations such as selfcentered and self-derogatory worry conditions and other irrelevant thoughts will increase. 
Drive models: These models propose that when there is so much drive or arousal in a particular testing situation, performance is weakened, particularly if the performance is not simple (Spence \& Spence, 1966 as cited in Zeidner, 1998). According to this model high anxiety will lead to a high drive level and consequently a competition among all possible responses, thereby leading to errors. This model assumes that an increase in the drive level strengthens both correct and incorrect responses. On the other hand when a test is easy, correct responses become dominant and drive levels increase the strength of these correct responses which has a facilitating effect.

The main source of anxiety in school is fear of failure and loss of self-Esteem (Hill \& Wigfield, 1984). Anxiety impedes school performance in many ways (Skalvik, 1997). Students may have difficulty in transferring their Knowledge showing it on a test (Bandalos, Yates, \& Thorndike-Christ, 1995). Some students are likely to be overly self-conscious and this can distract them from the task at hand (Tobias, 1992).

\section{RELATED STUDIES}

Research on the role of frequent testing began by the work of Ebbinghaus (as cited in Dempster, 1988). He found that the distribution of a large amount of material over a time space is more advantageous than the presentation of the whole material at once. Most of these studies are devoted to examining the effect of testing frequency on the scores of the students on the final exam. Here are some of these studies:

Shirvani (2009) conducted a study in which there were two experimental groups and two control groups. The experimental group took daily short quizzes and the control group took weekly quizzes. The participants in this study were Hispanic students in four geometry classes. He investigated whether daily quizzes had a significant effect on students' final exams scores and homework grades. The researcher found that daily quizzes had a significant effect on both of these dependent variables.

Momeni and Barinani (2012) investigated the effect of testing frequency on Iranian pre-intermediate EFL learners' language achievement. This study consisted of two experimental groups and one control group. One of the experimental groups received weekly quizzes and the other bi-weekly quizzes. The control group took no quizzes. The results showed that those students who took quizzes outperformed those who took no quizzes and the group with weekly quizzes outperformed those with bi-weekly quizzes on the final exam.

Gholami and Moradi Moghaddam (2013) examined the effect of weekly quizzes on students' final achievement score. The participants of this study were selected from among high school students in grade two. These students were divided into two groups. One group only took the midterm exam and the other group weekly quizzes. The results showed that the students with weekly quizzes outperformed those with only the mid-term exam.

Deck (1998) examined the effects of frequency of testing on college students in a principle of marketing course. The results showed a difference between the groups with weekly and monthly tests with the group who took weekly tests performing better than the group with monthly tests. However, the final scores of both groups were not significantly different. Also, the self-reported study hours of both groups were not significantly different.

Some other studies examine the role of feedback. In these studies after each test the students are given feedback on their answers.

Marcell (2008) compared the performance of two groups in introductory Psychology. One group took time limited, out of class WebCT quizzes on daily readings and the other group took no quizzes. Analysis of the results showed that quizzes lead to more questions and comments at the beginning of the class. Also the results indicated that those students who took quizzes read the material before coming to the class. The feedbacks helped the students diagnose their areas of weakness.

In addition to leading to better scores on the final exam, tests also increase class participation and preparation. Here are some of these studies:

Zarei (2010) examined the effect of quiz frequency on course performance and class attendance of Iranian university learners of English. This study consisted of five groups. Group 1 received no quizzes, group 2 received a mid-term exam, group 3 took monthly quizzes, group 4 took a quiz every other week, and group 5 received weekly quizzes. The results showed that more quizzes lead to a more successful course performance. The results also revealed that more frequent quizzes results in less absences from the class.

Dineen, Taylor and Stephens (2010) examined the effect of testing frequency upon the achievement of Students in high school mathematic courses. In this study one group of the students took daily quizzes and the other group weekly quizzes. The students with daily quizzes showed improvement, but this improvement was not significant.

Tests not only influence the scores of the students on the final exam, they also long-term retention of the information.

Butler and Roediger (2007) investigated the effect of testing on long-term retention in a simulated classroom setting. In this study three groups of participants were presented with three lectures. After the lectures participants were presented with three post lecture activity. One group studied a lecture summary. Another group took a multiple-choice test and the last group received a short answer test. Half of the responses of the multiple choice test and the short answer test were provided with feedback. One month later a final comprehensive short answer test was administered .The results showed that studying a lecture summary or tanking a short answer test was better than doing no activity for longterm retention of the material. Taking a short answer test had the most effect. 
Hancock (2001) examined the effect of learner characteristics, test anxiety and threat of evaluation on the achievement and motivation of students. The participants in this study were post-secondary students. On group of the students were placed in a high-evaluative condition. The results showed that all the students especially the test-anxious students when placed in a high-evaluative condition performed poorly and are less motivated.

Yamin (1988) examined the effect of frequency of testing on achievement, test anxiety, and attitudes toward science. The participants in this study were 278 Students of chemistry at the university technology of Malaysia. The students took a pre-test and post-test in achievement, test anxiety and attitudes toward science. State Trait Anxiety Inventory, Science Attitude Questionnaire, frequent tests and conventional tests were used as instruments to gather the data of this study. The experimental group took frequent tests, while the control group took conventional tests. The results indicated that frequent tests lead to better achievement and lower anxiety than conventional tests. The results also revealed that there is no significant difference between the control and experimental group in terms of their attitude toward science.

Dustin (1971) conducted a study in which there were two groups. One group took four parts of an exam in four weeks. The other group took all the four parts one month later. The results showed that the weekly-exam group gained a higher score in 3 out of 4 exam and experience less anxiety in each exam than the monthly-exam group. The results also revealed that the weekly-exam group gained a higher score in a delayed retention test.

Basol and Johanson (2009) conducted a meta-analysis of the studies which investigated the effectiveness of frequent testing over achievement. This consisted of 78 studies which were done until the year 2003. These studies were categorized into low, medium, and high frequent testing. The results indicated that the difference between the mean effect size for these categories was not significant. Overall, the findings showed that frequent administrations of tests improve academic achievement.

Phelps (2011) also conducted a meta-analysis on the effect of testing on achievement. This included studies which were done until the year 2009. The results indicated that testing followed by feedback has the strongest positive effect on achievement. Also, tests with high stakes strongly affect achievement. Overall, the result indicated that the effect of testing on achievement is moderate to strong.

\section{CONCLUSION}

In this review several studies on the role of frequent administrations of tests on students' motivation, anxiety, and the scores on the next tests were reviewed. Although most of our studies showed a positive effect for frequent administrations of tests, there were also some studies like Deck(1998), Dineen, Taylor, \& Stephens (2010), and Johanson's meta-analysis (2009) which showed that the effect of these frequent tests on study hours and students' scores is not significant or moderate (Richard ,2011). So, more studies are needed to confirm or disconfirm the effect of frequent administrations of tests.

\section{REFERENCES}

[1] Bachman, L. F. (1990). Fundamental considerations in language testing. New York: Oxford University Press.

[2] Bandalos, D. L., Yates, K., \&Thorndike-Christ, T. (1995).Effects of math self-concept, perceived self-efficacy and attributions for failure and success on test anxiety. Journal of Educational Psychology, 87(4), 611-623.

[3] Bangert-Drowns, R. L., Kulik, C.C., Kulik, J. A., \& Morgan, M.T. (1991).The instructional effect of feedback in test-like events.Review of Educational Research,61(2), 213-238.

[4] Bangert-Drowns, R. L., Kulik, J. A., \& Kulik, C.C. (1991). Effects of frequent classroom testing. Journal of Educational Research, 85(2), 89-99.

[5] Basol, G., \&Johnson, G. (2009). Effectiveness of frequent testing over achievement: a meta-analysis study. International Journal of Human Sciences, 6(2), 99-120.

[6] Benjamin, M., McKeachi, W. J., Lin, Y. J., \&Holinger, D. P. (1981).Test anxiety: Deficits in information processing. Journal of Educational Psychology, (73), 816-824.

[7] Blatt, S. J. (1995). The destructiveness of Perfectionism: Implications for the treatment of depression. American Psychologist, (50), 1003-1020.

[8] Brookhart, S. M., De Voge, J. G. (1999). Testing a theory about the role of classroom assessment in student motivation and achievement. Applied Measurement in Education, 12(4), 409-425.

[9] Brown, H. D. (2007). Principles of language learning and teaching. New York: Pearson Education, Inc.

[10] Butler, A. C., Roediger, H. L. (2007). Testing improves long-term retention in a stimulated classroom setting. European Journal of Cognitive Psychology, 19(4/5), 514-527.

[11] Carver, C. S., Scheier, M. F. (1988). Performing poorly, performing well: A view of the self-regulatory consequences of confidence and doubt. International Journal of Educational Research, 12, 325-332.

[12] Clump, M. A., Bauer, H., \& Alex, W. (2003).To attend or not to attend: Is that a good question?.The Internet TESOL Journal, 8 (12), Retrieved November 5, 2013 from http://findaricles.com/p/articles/mi.

[13] Covington, M. V. (1992). Making the grade. Cambridge: Cambridge University Press.

[14] Dempster, F. N. (1988). The spacing effect: A case study in the failure to apply the results of psychological research. American Psychologist, 43(8), 627-634.

[15] Dineen, P., Taylor, J., \&Stephens, L. (1989).The effect of testing frequency upon the achievement of students in high school mathematics course. School Science and Mathematics, 89(3), 197-200.

[16] Dustin, D. S. (1971).Some effects of exam frequency. The Psychological Record, 21(3), 409-414. 
[17] Duckworth., Kenneth. (1986). The relationship of high school classroom teacher's class testing to student's feelings of efficacy and effort to study. Retrieved November $5, \quad 2013$ from http://www.eric.ed.gov/ERICWebPortal/search/detailmini.jsp?_nfpb=true\&_\&ERICExtSearch_SearchValue_0=ED274676\&E RICExtSearch_SearchType_0=no\&accno=ED274676.

[18] Gholami, V., Morady Moghaddam, M. (2013).The effect of weekly quizzes on students' final achievement score. Modern Education and Computer Science, volume number(1), 36-41.

[19] Hancock, D. R. (2001).Effects of test anxiety and evaluative threat on students' achievement and motivation. The Journal of Educational Research, 94(5), 284-290.

[20] Harlen, W., \& Crick, R. D. (2002). A systematic review of the impact of summative assessment and tests on students' motivation for learning. EPPI Centre. Retrieved November 2, 2013 from http://eppi.ioe.ac.uk/cms/LinkClick.aspx?fileticket=Pbyl1CdsDJU\%3D\&tabid=106\&mid=1967.

[21] Hewitt, P. L., \& Flett, G. L. (1991).Perfectionism in the self and social context: Conceptualization, Assessment, and association with psychopathy. Journal of Personality and Social Psychology, (60), 456-470.

[22] Hill, K., \& Wigfield, A. (1984).A major educational problem and what can be done about it. Elementary School Journal, (85), 105-126.

[23] Marcell, M. (2008).Effectiveness of regular online quizzing in increasing class participation and preparation. International Journal for the Scholarship of Teaching and Learning, 2(1), 1-9.

[24] Momeni, A., Barimani, Sh. (2012). The effect of testing frequency on Iranian pre-intermediate EFL learners' language achievement. Journal of Academic and Applied Studies, 2(10), 76-87.

[25] Marshall, B. (2007).A crisis for efficacy. Education Review, 20(1), 29-35.

[26] Oliver, R. (1975). Overcoming test anxiety. Rational Living, (10), 6-12.

[27] Paulman, R. G., Kennelly, K. J. (1984). Test anxiety and ineffective test taking: Different names, same construct?. Journal of Educational Psychology, (76), 279-288.

[28] Baumgardner. (Eds).ESP in the classroom: Practice and evaluation (98-107).London: Modern English.

[29] Phelps, R. P. (2011). The effect of testing on student achievement. International Journal of Testing, 12(1), 21-43.

[30] Shirvani, H. (2009). Examining an assessment strategy on high school mathematics achievement. American Secondary Education, 38(1), 34-45.

[31] Skaalvik, E. M. (1997). Self-enhancing and self-defeating ego orientation: Relations with task and avoidance orientation, achievement, self-perceptions and anxiety. Journal of Educational Psychology, 89(1), 71-81.

[32] Smith, T. W., Snyder, C. R., \&Handelsman, M. M. (1982).On the self-serving function of an academic wooden leg: Testsanxiety as self-handicapping strategy. Journal of Personality and Social Psychology, (44), 1276-1283.

[33] Spielberger, C. D., Gonzales, H. P., Taylor, C. J., Algaze,B., \& Anton W.D. (1978). Examining stress and test-anxiety. In C.D. Spielberger \& I.G. Sarason (Eds.), stress and anxiety (Vol.5, PP. 167-191). New York: Wiley.

[34] Spielberger, C.D., \& Vag, P.R. (1995).Test anxiety: Theory, assessment, and treatment. Washington, DC: Taylor \& Francis.

[35] Tobias, S. (1992). The impact of test anxiety cognition in school learning. Advances in Test Anxiety Research, 7, 18-31.

[36] Weimer, M. (2003). Focus on learning, transform teaching. Heldref Publications.

[37] Weinstein, C. E., Cubberly, W. E., \& Richardson, F. C. (1982). The effects of test anxiety on learning at superficial and deep levels of processing. Contemporary Educational Psychology, 7, 107-112.

[38] William Deck, D. (1998). The effects of frequency of testing on college students in a principle of marketing course. Retrieved November 3, 2013 fromhttp://scholar.lib.vt.edu/theses/available/etd110298195932/unrestricted/dis.pdf.

[39] Yamin, S.B. (1988). Frequency of testing and its effects on achievement in Chemistry, test anxiety, and attitudes toward science at University Technology of Malaysia. Retrieved November 1, 2013 from http://ir.library.oregonstate.edu/xmlui/bitstream/handle/1957/28982/YaminSulaimanBin1989.pdf?sequence=1.

[40] Zarei, A.A. (2010). Course performance: the effect of quiz frequency on course performance and its relationship with class attendance of Iranian university learners of English. Journal of Persian Language and Literature, (26), 52-69.

[41] Zeidner, M. (1998). Test Anxiety: The State of the Art. New York: Plenum Publishers.

Mostafa Hosseyni Ramshe was born in Ramshe, Isfahan city, Iran in 6.6.1988. He received his B.A. in English translation studies from University of Isfahan in 2011. He furthered his university studies on English education, and received his M.A. in TEFL from University of Isfahan in 2013. 